\title{
Comparison of Plain Ropivacaine and Ropivacaine with Dexmedetomidine in Caudal Epidural Block for Paediatric Infra Umbilical Surgery.
}

\author{
Manish Kumar Modi', Geetanjali Singhal', BL Mathur', Neena Rungta', Sapna Singh ${ }^{1}$, L.D. Agrawal ${ }^{2}$ \\ ${ }^{1}$ Department of Anaesthesiology, JNU Medical College, Jaipur, India, ${ }^{2}$ Department of Paediatric Surgery, JNU Medical College, Jaipur.
}

\section{Abstract}

Background: Context: Caudal analgesia is reliable and safe method for perioperative analgesia in paediatric patients for infraumbilical surgeries. To prolong the duration of caudal block, many additives are added with local anesthetics. Aim: To compare the effects of ropivacaine and dexmedetomidine mixture with plain ropivacaine in caudal block in paediatric infra umbilical surgeries. Subjects and Methods: Sixty patients of ASA grade 1 and 2, aged 6 month to 10 year, undergoing below umbilicus surgery, were divided into two groups of 30 each. Group R received $0.25 \%$ ropivacaine $(1 \mathrm{ml} / \mathrm{kg})$ with $0.5 \mathrm{ml}$ normal saline and group RD received $0.25 \%$ ropivacaine $(1 \mathrm{ml} / \mathrm{kg})$ with dexmedetomidine $(1 \mu \mathrm{g} / \mathrm{kg})$ in $0.5 \mathrm{ml}$ normal saline. Results: The duration of postoperative analgesia was significantly longer and the requirement of rescue analgesia was significantly lower in group RD as compared to group R. Conclusion: Caudal Ropivacaine $(0.25 \%)$ with dexmedetomidine $(1 \mu \mathrm{g} / \mathrm{kg})$ proved more effective than plain ropivacaine $(0.25 \%)$ in providing analgesia in paediatric infraumbilical surgeries.

Keywords: Caudal, Ropivacaine, Dexmedetomidine, Postop Analgesia.

Corresponding Author: Dr Geetanjali Singhal, 4- Raghav apartments, A-33, Shyam Nagar, Jaipur -302019, Rajasthan, India.

Received: September 2019

Accepted: September 2019

\section{Introduction}

Intra operative \& Post-operative analgesia have always been a challenge in paediatric surgery. Response to pain is very different in paediatric patients as they not only feel the pain, but may also develop emotional disorders. Pain is difficult to assess in this age group of patients. Caudal block is a wellaccepted technique $\&$ provides both intra \& post op analgesia in paediatric group. It is easy to perform and safe. It reduces the requirement of volatile agent and opioids in paediatric patients thereby reducing the incidence of post op nausea and vomiting and allowing fast and smooth recovery. ${ }^{[1]}$

Usage of single local anaesthetic agent for caudal block provides shorter duration of analgesia. ${ }^{[2]}$ In our study we added adjuvant (Dexmedetomidine) to Ropivacaine for prolonging the duration of analgesia.

Ropivacaine being a less lipophilic local anaesthetic results in less motor blockage and prolongs sensory analgesia, therefore proving a better choice. ${ }^{[3]}$

Dexmedetomidine is a $\alpha 2$ agonist and it possesses anxiolytic, sedative, sympatholytic and analgesic properties without causing any respiratory depression. ${ }^{[4]}$

We did a prospective randomized double blind study to compare plain Ropivacaine with Ropivacaine and Dexmedetomidine mixture in paediatric caudal epidural block.

\section{Subjects and Methods}

This study was conducted in 60 children of ASA grade 1 and 2 , aged 6 Approval from the ethical committee of the institute and written informed consent from the parents of the patients were obtained. Patients were excluded if they had history of developmental delay or mental retardation, local infection, bleeding disorder, spinal deformity or parental refusal.

In pre-anaesthesia checkup patient's age, weight and baseline vital parameters were recorded. Routine lab Investigation was carried out for all patients. Patients were kept fasting (6 hrs for solid, $4 \mathrm{hrs}$ for breast milk and $2 \mathrm{hrs}$ for clear fluids) as per the protocol.

Patients were randomly allocated into two groups- Group R (Ropivacaine) and Group RD (Ropivacaine + Dexmedetomidine) by using a computer generated list.

1. Group $\mathrm{R}$ received $0.25 \%$ Ropivacaine $1 \mathrm{ml} / \mathrm{kg}+0.5 \mathrm{ml}$ normal saline

2. Group RD received $0.25 \%$ Ropivacine $1 \mathrm{ml} / \mathrm{kg}+1 \mu \mathrm{g} / \mathrm{kg}$ Dexmedetomidine (in $0.5 \mathrm{ml}$ volume).

Anaesthesiologist who conducted the anaesthetic procedures including monitoring of the patients post operatively was unaware of the group allocation and the person who prepared the drug was excluded from further contact with patient. 
On receiving the patient in OT all basic monitors were attached and baseline parameters including blood pressure, heart rate, $\mathrm{SpO}_{2}$, and respiratory rate were recorded. IV fluid was started at a rate of $4 \mathrm{ml} / \mathrm{kg} / \mathrm{h}$.

In our study no premedication and no muscle relaxant was used. Induction of anaesthesia was done with $8 \%$ sevoflurane and $100 \%$ oxygen by bag and mask ventilation. After proper relaxation appropriate size of LMA was inserted. Bilateral air entry was checked and Sevoflurane concentration was reduced to $3 \%$ with fresh gas flow of $3-41 / \mathrm{min}$.

Patient was placed in left lateral decubitus position and caudal epidural block was performed under all aseptic conditions with 21 or 22 gauge needle. After negative aspiration the drug was injected, time of injection noted and patient placed in supine position. Throughout the surgical procedure anaesthesia was maintained with sevoflurane and oxygen. The concentration of sevoflurane was adjusted to maintain the haemodynamic changes within $20 \%$ of the baseline. No other drug was injected intraoperatively.

Haemodynamic parameters like B.P, Pulse rate, Respiratory rate and $\mathrm{spo} 2$ were recorded at the time of induction and at 2,5,10,15,20,25 and 30 minute intervals. Following this half hourly monitoring was done till the completion of surgery. In the post operative period half hourly monitoring was done.The postop pain was assessed with the use of FLACC pain scale. ${ }^{[5]}$ The duration of analgesia and total dose of rescue analgesics was also recorded.

Adverse effects like nausea, vomiting, bradycardia, hypotension etc were recorded and treated.

\section{Results}

Both groups had no significant difference in age, weight, gender, type and duration of surgery [Table 1]. There is no significant difference in intraoperative and postoperative haemodynamic changes (HR and mean arterial pressure) [Figure 1]

Table 1: Statistical Analysis
\begin{tabular}{|l|l|l|l|}
\hline Variables & Ropivacaine & $\begin{array}{l}\text { Ropivacaine }+ \\
\text { Dexmedetomidine }\end{array}$ & P-Value \\
\hline Age(years) & $5.35 \pm 1.102$ & $4.27 \pm 1.02$ & 0.1698 \\
\hline Weight(kg) & $16.57 \pm 2.82$ & $13.6 \pm 1.54$ & 0.082 \\
\hline Heart Rate & $126 \pm 5.1$ & $131 \pm 6.3$ & 0.2626 \\
\hline SPO2 & $99 \pm 0.3$ & $99 \pm 0.3$ & 0.999 \\
\hline $\begin{array}{l}\text { Blood } \\
\begin{array}{l}\text { Pressure } \\
\text { Systolic) }\end{array}\end{array}$ & $115 \pm 3.2$ & $115 \pm 3.93$ & 0.89 \\
\hline $\begin{array}{l}\text { Blood } \\
\text { Pressure } \\
\text { (Diastolic) }\end{array}$ & $74 \pm 3$ & $73 \pm 3$ & 0.5956 \\
\hline
\end{tabular}

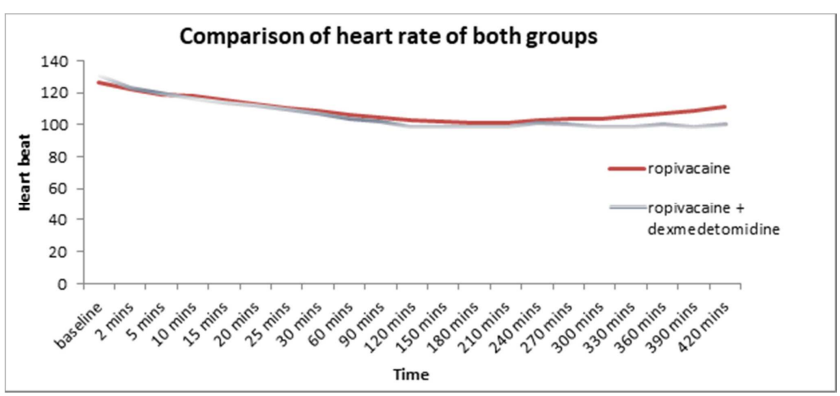

Figure 1: Comparison of heart rate of both groups
In our study mean of onset of block was 14.17 min in group $\mathrm{RD}$ while in group $\mathrm{R}$ mean was 18.2 min with a $\mathrm{P}$ value of .0000001 [Figure 2]. Mean of duration of analgesia was 698 min in group $\mathrm{RD}$ while in group $\mathrm{R}$ it was 372 min with a $\mathrm{p}$ value of .000001 [Figure 3]. Postoperative after $3 \mathrm{hrs}$ there were adequate analgesia (FLACC score $<4$ ) in all patients of both group. There after the effect declined in group R .At 6 hr postoperative, FLACC score was $>4$ in $40 \%$ patients of group $\mathrm{R}$ as compared to $0 \%$ in group RD. FLACC score was $>4$ in $40 \%$ patients of group $\mathrm{RD}$ at $12 \mathrm{hr}$ postoperative [Figure 5]. Mean Time of rescue analgesia was $411 \mathrm{~min}$ in group $\mathrm{R}$ as compared to group RD 776 min with a p value of .0000001. [Figure 4]

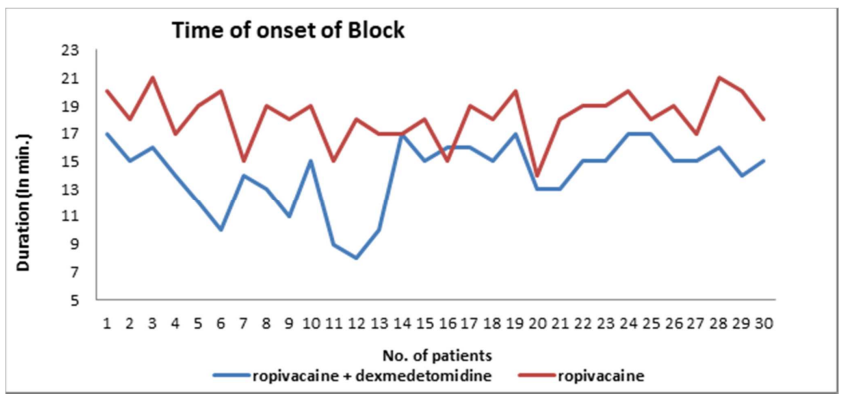

Figure 2: Time of onset of Block

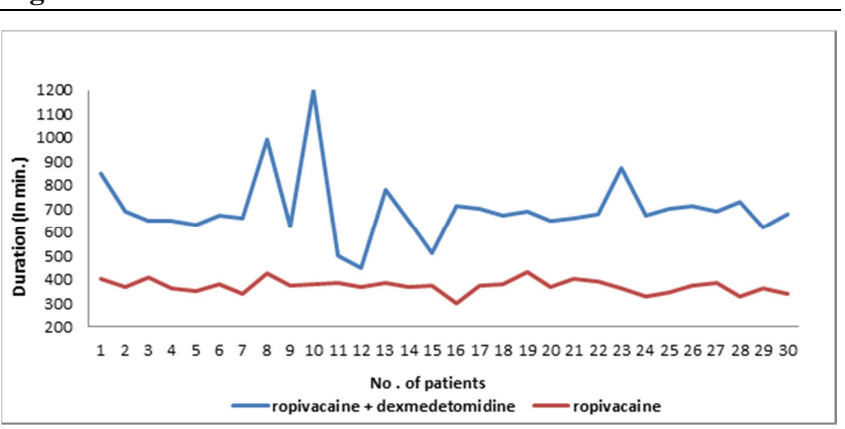

Figure 3: Duration of Analgesia

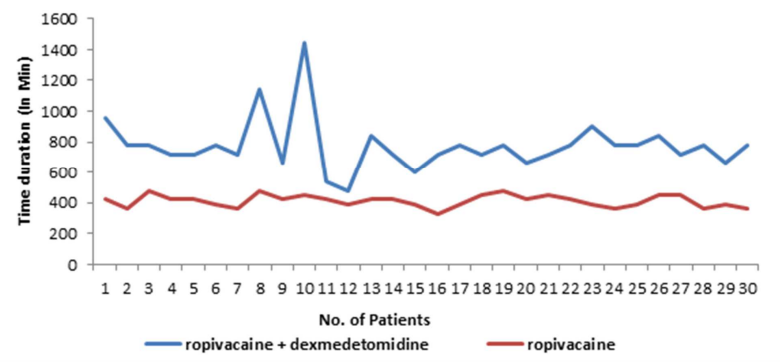

Figure 4: Time for Rescue Analgesia

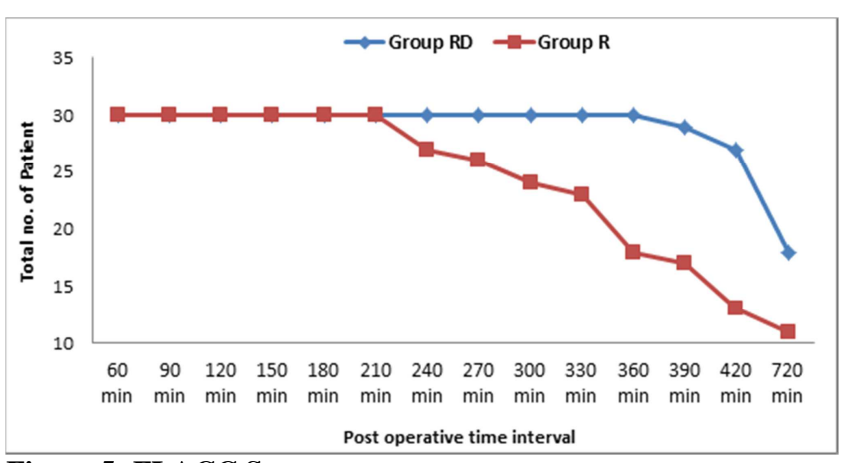

Figure 5: FLACC Score 


\section{Discussion}

Pain is very difficult to assess in children. Therefore postop pain remains undertreated in this age group. There are various methods to provide postop analgesia in children. ${ }^{[6,7]}$ Caudal epidural block is safe and a well accepted technique. ${ }^{2]}$ Various drugs like opioids, midazolam, ketamine, $\alpha 2$ - agonist etc,were used in caudal block to improvise postop analgesia. ${ }^{[8-10]}$ The use of opioids in caudal block may be associated with side effects like respiratory depression, pruritis and urinary retention. ${ }^{[11,12]}$ These side effects can be avoided with use of caudal $\alpha 2$ - agonist.

Ropivacaine is safer, less cardiotoxic and has less motor blockage as compared to bupivacaine. ${ }^{[13]}$

Dexmedetomidine and clonidine, both are $\alpha 2$ - agonist agents. Dexmedetomidine is more selective for A subtype of $\alpha 2$ receptor than clonidine. Therefore it has less cardiovascular side effects in comparison to clonidine. ${ }^{[14]}$ According to some studies dexmedetomidine can be used safely in neuraxial blocks without any neurological deficit. ${ }^{[15-17]}$

In our study, we had two groups. In group RD we gave dexmedetomidine $1 \mu \mathrm{g} / \mathrm{kg}$ with ropivacaine $0.25 \%(1 \mathrm{ml} / \mathrm{kg})$ in caudal epidural space and in the other group $\mathrm{R}$ we gave only ropivacaine $0.25 \%(1 \mathrm{ml} / \mathrm{kg})$. We observed that the duration of postop analgesia was significantly longer in group RD (698 min) than the group R (372 min), with $p$ value of .000001 . Anand et al, ${ }^{[18]}$ observed that when dexmedetomidine was given in a dose of $2 \mu \mathrm{g} / \mathrm{kg}$ as an adjuvant with $0.25 \%$ ropivacaine the duration of analgesia was significantly longer in group RD $(14.5 \mathrm{hr})$ than the R group $(5.5 \mathrm{hr})$. EL-Hennawy et al, ${ }^{[19]}$ administered dexmedetomidine and clonidine, both in a dose of $2 \mu \mathrm{g} / \mathrm{kg}$ as an adjuvant with $0.25 \%$ bupivacaine caudally. They observed that the duration of analgesia was significantly longer in the group receiving bupivacaine -dexmedetomidine mixture (median $\{95 \% \mathrm{CI}\}: 16 \mathrm{~h}\{14-18\}$ ) or bupivacaineclonidine mixture (median $\{95 \% \mathrm{CI}\}: 12 \mathrm{~h}\{3-21\}$ ) than the group receiving bupivacaine alone(median $\{95 \% \mathrm{CI}\}: 5 \mathrm{~h}\{4-$ $6\})$. Neogi et al. (20) compared clonidine $(1 \mu \mathrm{g} / \mathrm{kg})$ and dexmedetomidine $(1 \mu \mathrm{g} / \mathrm{kg})$ as adjuvants to ropivacaine 0.25 $\%$ for caudal analgesia in paediatric patients and found that mean duration of analgesia was $15.26(0.86) \mathrm{hr}$ in dexmedetomidine group, which was significantly longer than both clonidine group $13.17(0.68) \mathrm{hr}$ and ropivacaine group $6.32(0.46) \mathrm{h}$.

In present study, we observed that the time 'to first rescue analgesia was significanty longer in group RD as compared to group R. Saadway et al. ${ }^{[21]}$ observed that the duration of analgesia was significantly longer in group receiving bupivacaine- dexmedetomidine mixture caudally than the group receiving bupivacaine alone.

The perioperative hemodynamic variables [Table 1] were comparable and not statistically significant. There is no significant postoperative complications such as nausea, vomiting, respiratory depression, hypotension, bradycardia etc. In our study, we observed that dexmedetomidine prolonges postoperative analgesia with a favorable safety profile and stable hemodynamics, which was also published by several other authors. ${ }^{[19,22-24]}$

\section{Conclusion}

On the basis of our results, we concluded that the addition of dexmedetomidine $(1 \mu \mathrm{g} / \mathrm{kg})$ to caudal ropivacaine $0.25 \%$ (1 $\mathrm{ml} / \mathrm{kg}$ ) for paediatric infraubilical surgeries achieved significant postoperative pain relief without increasing the incidence of side effects.

\section{References}

1. Silvani P, Camporesi A, Agostino MR, Salvo I. Caudal anesthesia in Paediatrics: An update. Minerva Anestesiol 2006;72:453-9

2. Verghese ST, Hannallah RS. Postoperative pain management in children. Anesthesiol Clin North America. 2005;23:163-84.

3. Habre W, Bergesio R, Johnson C, Hackett P, Joyce D, Sims C, et al. Pharmacokinetics of ropivacaine following caudal analgesia in children. Paediatr Anaesth. $2000 ; 10: 143-7$

4. Hall JE, Uhrich TD, Barney JA, Arain SR, Ebert TJ. Sedative, amnestic,and analgesic properties of small-dose dexmedetomidine infusions. Anesth Analg 2000;90:699-705.

5. Merkel SI, Voepel-Lewis T, Shayevitz JR, Malviya S. The FLACC: A behavioral scale for scoring postoperative pain in young children. Pediatr Nurs 1997;23:293-7

6. Lloyd-Thomas AR. Pain management in paediatric patients. Br J Anesth 1990;64:85-104.

7. Verghese ST, Hannallah RS. Postoperative pain management in children. Anesthesiol Clin North America 2005;23:163-84

8. De Beer DA, Thomas ML. Caudal additives in children - Solutions or problems? Br J Anesth 2003;90:487-98.

9. Birbicer H, Doruk N, Cinel I, Atici S, Avlan D, Bilgin E, et al. Could adding magnesium as adjuvant to ropivacaine in caudal anesthesia improve postoperative pain control? Pediatr Surg Int 2007;23:195-8.

10. Vetter TR, Carvallo D, Johnson JL, Mazurek MS, Presson RG Jr. A comparison of single-dose caudal clonidine, morphine, or hydromorphone combined with ropivacaine in pediatric patients undergoing ureteral reimplantation. Anesth Analg 2007;104:1356-63.

11. Gedney JA, Liu EH. Side-effects of epidural infusions of opioid bupivacaine mixtures. Anesthesia 1998;53:1148-55.

12. Krane EJ. Delayed respiratory depression in a child after caudal epidural morphine. Anesth Analg 1988;67:79-82.

13. Ray M, Mondal SK, Biswas A. Caudal analgesia in pediatric patients: Comparison between bupivacaine and ropivacaine. Indian J Anesth 2003;47:275-8

14. Civantos Calzada B, Aleixandre de Artiñano A. $\alpha 2$ adrenoceptor subtypes. Pharmacol Res 2001;44:195-208

15. Mason LJ.The Use of alpha-2Agonist in Pediatric Patient. Forty-seventh Clinical Conference in Pediatric Anesthesiology. Available from: http:// www.pac.chla-accm.org/Abstracts/CONF46_01252008-1900ABLMason.pdf. [Last accessed on $2009 \mathrm{Feb}$ ].

16. Vieira AM, Schnaider TB, Brandão AC, Pereira FA, Costa ED, Fonseca CE. Epidural clonidine o $\mathrm{r}$ dexmedetomidine for post-cholecystectomy analgesia and sedation. Rev Bras Anestesiol 2004;54:473-8

17. Schnaider TB, Vieira AM, Brandão AC, Lobo MV. Intraoperative analgesic effect of epidural ketamine, clonidine or dexmedetomidine for upper abdominal surgery. Rev Bras Anestesiol 2005;55:525-31.

18. Anand VG, Kannan M, Thavamani A, Bridgit MJ. Effects of dexmedetomidine added to caudal ropivacaine in paediatric lower abdominal surgeries. Indian J Anesth 2011;55:340-6.

19. El-Hennawy AM, Abd-Elwahab AM, Abd-Elmaksoud AM, ElOzairy HS, Boulis SR. Addition of clonidine or dexmedetomidine to bupivacaine prolongs caudal analgesia in children. Br J Anesth 2009; 103:268-74

20. Neogi M, Bhattacharjee DP, Dawn S, Chatterjee N. A comparative study between clonidine and dexmedetomidine used as adjuncts to ropivacaine for caudal analgesia in pediatric patients. J Anesth Clin Pharmacol 2010; 26:149-53

21. Saadawy I, Boker A, Elshahawy MA, Almazrooa A, Melibary S, Abdellatif AA, et al. Effect of dexmedetomidine on the characteristics of bupivacaine in a caudal block in pediatrics. Acta Anesthesiol Scand 2009;53:251-6

22. YoshitomiT, KohjitaniA, Maeda S, Higuchi H, Shimada M, MiyawakiT. Dexmedetomidine enhances the local anesthetic action of lidocaine via an $\alpha 2 \mathrm{~A}$ adrenoceptor. Anesth Analg 2008;107:96-101. 
23. Petroz GC, Sikich N, James M, van Dyk H, Shafer SL, Schily M, et al. A phase I, two-center study of the pharmacokinetics and pharmacodynamics of dexmedetomidine in children. Anesthesiology
2006; $105: 1098-110$

24. Tobias JD, Berkenbosch JW. Initial experience with dexmedetomidine in paediatric-aged patients. Paediatr Anesth 2002;12:171-5

Copyright: ( ) the author(s), publisher. Academia Anesthesiologica International is an Official Publication of "Society for Health Care \& Research Development". It is an open-access article distributed under the terms of the Creative Commons Attribution Non-Commercial License, which permits unrestricted non-commercial use, distribution, and reproduction in any medium, provided the original work is properly cited.

How to cite this article: Modi MK, Singhal G, Mathur BL, Rungta N, Singh S, Agrawal LD. Comparison of Plain Ropivacaine and Ropivacaine with Dexmedetomidine in Caudal Epidural Block for Paediatric Infra Umbilical Surgery. Acad. Anesthesiol. Int. 2019;4(2):205208.

DOI: dx.doi.org/10.21276/aan.2019.4.2.47

Source of Support: Nil, Conflict of Interest: None declared. 